\title{
Phosphorylation of histone $\mathrm{H} 3$ on Ser10 by auto-phosphorylated PAK1 is not essential for chromatin condensation and meiotic progression in porcine oocytes
}

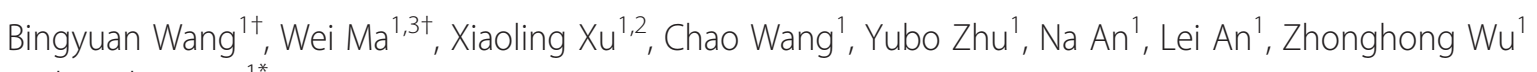
and Jianhui Tian ${ }^{1 *}$

\begin{abstract}
Background: The p21-activated kinase 1 (PAK1) is essential for mitosis and plays an important role in the regulation of microtubule assembly during oocyte meiotic maturation in mice; however, little is known about its role in porcine oocytes.

Result: Total p21-activated kinase 1 (PAK1) and phosphorylated PAK1 at Thr423 (PAK1 ${ }^{\text {Thr423) }}$ ) were consistently expressed in porcine oocytes from the germinal vesicle (GV) to the second metaphase (MII) stages, but phosphorylation of histone $\mathrm{H} 3$ at Ser10 $\left(\mathrm{H}^{\mathrm{Ser} 10}\right)$ was only expressed after the GV stage. Immunofluorescence

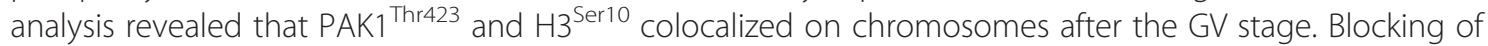
endogenous PAK $1^{\text {Thr } 423}$ by injecting a specific antibody decreased the phosphorylation level of $\mathrm{H}^{\text {Ser10 }}$; however, it had no impact on chromatin condensation, meiotic progression, cleavage rate of blastomeres or the rate of blastocyst formation.

Conclusion: Phosphorylation of PAK $1^{\text {Thr423 }}$ is a spontaneous activation process and the activated PAK $1^{\text {Thr } 423}$ can promote the phosphorylation of $\mathrm{H}^{\mathrm{Ser} 10}$; however, this pathway is not required for meiotic maturation of porcine oocytes or early embryonic development.
\end{abstract}

Keywords: Chromosome condensation, $\mathrm{H3}^{\mathrm{Ser} 10}$, Meiotic progression, PAK1 ${ }^{\text {Thr }}{ }^{2}$, Porcine oocyte

\section{Background}

At birth, mammalian oocytes are arrested at prophase I when the nucleus is referred to as a germinal vesicle (GV), in which the chromatin is not condensed. During oocyte growth, chromatin in the GV condenses into perinucleolar rings [1]. After being stimulated by a preovulatory gonadotropin surge or when released from their surrounding follicular cells into suitable culture conditions, oocytes spontaneously resume meiosis, GV breakdown (GVBD) occurs and the chromatin is condensed into chromosomes.

\footnotetext{
* Correspondence: tianjh@cau.edu.cn

${ }^{\dagger}$ Equal contributors

'Ministry of Agriculture Key Laboratory of Animal Genetics, Breeding and Reproduction; National Engineering Laboratory for Animal Breeding, College of Animal Science and Technology, China Agricultural University, Beijing 100193, P. R. China

Full list of author information is available at the end of the article
}

Chromosome condensation, as the first visible process during oocyte maturation, is essential for the correct packaging of chromatin fibers into chromosomes and their proper segregation during meiotic maturation. Recent studies have shown that histone modifications during oocyte development are crucial for oocyte maturation in mammals and that disruption of these modifications leads to defective chromosome condensation and segregation, inevitably leading to delayed maturation [2]. Histone $\mathrm{H} 3$ is one of the core histones bound to DNA in the nucleosomes and the phosphorylation of histone $\mathrm{H} 3$ at serine $10\left(\mathrm{H} 3^{\text {Ser10}}\right)$ has been characterized extensively [3-8]. In SKN and HeLa cells, $\mathrm{H} 3{ }^{\mathrm{Ser} 10}$ regulates protein-protein interactions that drive and coordinate chromatin condensation as cells enter the M-phase of mitosis [3]. During meiosis in the mouse ovary, the dynamic expression of $\mathrm{H}^{\text {Ser10 }}$ has been related to

\section{Biomed Central}


changes in chromatin condensation [6]. In pig oocytes, a low level of $\mathrm{H}^{\mathrm{Ser} 10}$ is observed in GVs, which dramatically increased in all chromosomes from pro-metaphase I (ProMI) to the second metaphase (MII) [7]. Despite the dynamic expression of $\mathrm{H} 3{ }^{\mathrm{Ser} 10}$ and its localization on chromatin, $\mathrm{H} 3{ }^{\mathrm{Ser} 10}$ was not found to be essential for chromatin condensation in pig oocytes; however, it might be required for further processing of chromosomes during meiosis [9].

It could be speculated that $\mathrm{H} 3{ }^{\mathrm{Ser} 10}$ plays a different role during oocyte meiosis between mice and pigs, but evidence is needed to determine the definite function of $\mathrm{H}^{\mathrm{Ser} 10}$ in pig oocytes. Phosphorylation of $\mathrm{H}_{3}^{\mathrm{Ser} 10}$ can be regulated by multiple kinases [10,11]; for example, Aurora B has been shown to be an important kinase in vivo [12]. Inhibition of Aurora B significantly decreases the level of $\mathrm{H}^{\mathrm{Ser} 10}$ in mouse oocytes, resulting in chromosome misalignment [13]. In maturing porcine oocytes, activation of Aurora B precedes the phosphorylation of $\mathrm{H}_{3}^{\mathrm{Ser} 10}$ [9]. Moreover, treatment of immature porcine oocytes with the protein phosphatase 1/2a (PP1/2a) inhibitors, okadaic acid and calyculin A, induced rapid chromosome condensation with hyperphosphorylation of $\mathrm{H} 3^{\text {Ser10 }}$ [14]. Whether $\mathrm{H}^{\mathrm{Ser} 10}$ is directly responsible for catalyzing chromatin condensation during porcine oocyte meiosis, or if any other kinases are involved in this process, remains to be elucidated as the underlying mechanisms are not fully understood.

The p21-activated kinase (PAK) family belongs to a group of serine/threonine kinases, which have been identified as targets of the Rho GTPases Rac1 and Cdc42 [15,16]. The PAK family includes six PAK isoforms (PAK 1-6), which are composed of an N-terminal p21 GTPase-binding domain and a C-terminal kinase domain [17]. Specifically, PAK1 contains a PAK auto-inhibitory domain in the Nterminal regulatory domain, which can inhibit kinase activation by interaction with the catalytic domain $[18,19]$. Phosphorylation of PAK1 on threonine 423 (PAK1 $^{\text {Thr423 }}$ ), is a key event in PAK1 activation and is important for maintaining its relief from auto-inhibition [20]. The activated form of PAK1 behaves like a chromosomal passenger protein and can interact with and phosphorylate $\mathrm{H}^{\mathrm{Ser} 10}$ [21]. The literature suggests that the PAK1-histone H3 pathway is potentially involved in regulating mitotic events, such as chromatin condensation and subsequent chromosomal capture, movement and segregation [21]. It is not fully understood whether PAK1-mediated phosphorylation of histone $\mathrm{H} 3$ is conserved in mammalian oocytes during meiosis. Indeed, recent studies have shown that depleted expression of PAK1 in mouse oocytes lead to defects in meiotic spindle assembly, chromosome alignment and polar body extrusion, but the functional mechanism was not presented and needs to be clarified [22].

Given the uncertainty on the importance of the PAK1histone $\mathrm{H} 3$ pathway in oocyte maturation, we examined the expression and subcellular distribution of PAK1 $1^{\text {Thr423 }}$ and its relationship with $\mathrm{H} 3{ }^{\mathrm{Ser} 10}$ in porcine oocytes during meiotic maturation. Our results provide strong evidence that the phosphorylation of histone $\mathrm{H} 3^{\mathrm{Ser} 10}$ is regulated by PAK1 ${ }^{\text {Thr423 }}$; however, this regulation is not required for oocyte chromatin condensation and meiotic progression, or for subsequent embryonic development.

\section{Materials}

\section{Chemicals and antibodies}

All chemicals were purchased from Sigma-Aldrich (St. Louis, MO, USA) unless otherwise indicated. The rabbit polyclonal anti-PAK1 antibody was purchased from Signalway Antibody Co. (Ab-212; Pearland, TX, USA), the rabbit polyclonal anti-phosphorylated PAK1 (Thr423) antibody was purchased from Abgent Primary Antibody Co. (San Diego, CA, USA) and the monoclonal mouse antiphosphorylated Histone H3 (Ser10) antibody was purchased from Millipore Corp. (Billerica, MA, USA).

\section{Porcine oocyte collection and culture}

Ovaries of prepubertal gilts were collected at a local commercial slaughterhouse. Porcine cumulus cell-oocyte complexes were aspirated from the antral follicles in the ovaries as described [23]. Cumulus cell-oocyte complexes with evenly granulated cytoplasm were selected and cultured in TCM-199 medium (Gibco, Grand Island, NY, USA) containing $10 \%$ porcine follicular fluid, $0.1 \mathrm{mg} / \mathrm{mL}$ L-cysteine, $10 \mathrm{ng} / \mathrm{mL}$ epidermal growth factor, $10 \mathrm{IU} / \mathrm{mL}$ equine chorionic gonadotropin and $10 \mathrm{IU} / \mathrm{mL}$ human chorionic gonadotropin at $38.5^{\circ} \mathrm{C}$ in $100 \%$ humidity under an atmosphere of $5 \% \mathrm{CO}_{2}$ in air.

\section{Western blotting}

One hundred porcine oocytes released from cumulus cells were collected at different time points and frozen in $2 \times$ Laemmli sample buffer (Bio-Rad, Hercules, CA, USA) containing protease inhibitors. Prior to analysis, the samples were thawed and subsequently heated to $100^{\circ} \mathrm{C}$ for $5 \mathrm{~min}$. The proteins were then separated on a $12 \%$ polyacrylamide gel containing $0.1 \%$ sodium dodecyl sulfate and then transferred onto a poly(vinylidene fluoride) membrane (Amersham, Piscataway, NJ, USA). The membranes were blocked in Tris-buffered saline containing $0.05 \%(\mathrm{v} / \mathrm{v})$ Tween-20 with $5 \%$ non-fat dried milk overnight at $4{ }^{\circ} \mathrm{C}$ and incubated with polyclonal rabbit anti-PAK1 antibody $(1: 1,000)$, polyclonal rabbit anti-phosphorylated PAK1 (Thr423) antibody $(1: 1,000)$ or monoclonal mouse antiphosphorylated Histone H3 (Ser10) antibody (1:500) for $2 \mathrm{~h}$ at room temperature. Finally, peroxidase-conjugated secondary antibody (Jackson ImmunoResearch, West Grove, PA, USA) was added for $1 \mathrm{~h}$ and protein bands were then detected using an ECL-plus system (Amersham). 
Immunofluorescence analysis and confocal microscopy

Oocytes at different time points were fixed in $2 \%$ paraformaldehyde in phosphate buffered saline (PBS) for at least $30 \mathrm{~min}$ at room temperature and then incubated in PBS plus $1 \%$ Triton X-100 for $30 \mathrm{~min}$ at room temperature, followed by blocking in $1 \% \mathrm{BSA}$ at $4^{\circ} \mathrm{C}$ overnight. The oocytes were incubated for $2 \mathrm{~h}$ at $37^{\circ} \mathrm{C}$ with monoclonal anti-phosphorylated histone H3 (Ser 10) antibody (1:500 dilution), polyclonal rabbit anti-phosphorylated PAK1 (Thr423) antibody (1:1,000 dilution) or anti-acetylated tubulin antibody (1:10,000 dilution). The oocytes were then labeled with Alexa Fluor 594-labeled Goat anti-Rabbit or Alexa Fluor 488-labeled Goat anti-Mouse (Molecular Probes, Eugene, OR, USA) secondary antibodies for $1 \mathrm{~h}$ at room temperature in the dark. After washing, the oocytes were stained with [4/], 6-diamidino-2-phenylindole (DAPI; Sigma-Aldrich) to detect DNA and examined using a confocal laser scanning microscope (Zeiss LSM 510 META, Carl Zeiss GmbH, Jena, Germany).

\section{Chromosomal spreading analysis}

The zona pellucida of oocytes was removed by exposure to acid Tyrode's solution (pH 2.5). Zona-free oocytes then were fixed by carefully placing them onto a microscope slide dipped in a solution of $1 \%$ paraformaldehyde in distilled $\mathrm{H}_{2} \mathrm{O}$ containing $0.5 \%$ Triton X-100 [6]. To analyze the localization of PAK1 $1^{\text {Thr } 423}$ and $\mathrm{H} 3^{\mathrm{Ser} 10}$ on chromosomes, the slides were incubated with polyclonal rabbit anti-phosphorylated PAK1 (T423) antibody (1:500) and monoclonal mouse anti-phosphorylated Histone H3 (Ser10) antibody (1:250) in PBS for $1 \mathrm{~h}$ at $37^{\circ} \mathrm{C}$. This was followed by incubation with Alexa Fluor 594-labeled goat anti-rabbit IgG (1:500 dilution) and Alexa Fluor-labeled 488 goat anti-mouse IgG secondary antibodies (Molecular Probes) for $1 \mathrm{~h}$ at room temperature. After the chromosomes had been counterstained with DAPI, the samples were analyzed by an investigator blinded to their treatment group, at $1000 \times$ magnification using a Zeiss LSM 510 META microscope (Carl Zeiss GmbH, Jena, Germany).

\section{Antibody microinjection into oocytes}

Anti-PAK1 ${ }^{\text {Thr423 }}$ antibody (stock solution, $100 \mu \mathrm{g} / \mathrm{mL}$ ) was injected into the cytoplasm of zona-intact denuded oocytes at the GV stage, with normal rabbit IgG-injected oocytes and non-injected oocytes used as controls [24]. Sterile Femtotip capillaries and a FemtoJet microinjector (Eppendorf, Westbury, NY, USA) were used to standardize the injection volumes; an injection volume of $\sim 5 \mathrm{pL}$ per oocyte was used in all experiments. Ten micrograms of cycloheximide (CHX) per milliliter was added to the manipulation medium to prevent GVBD. After microinjection, oocytes were washed thoroughly with TCM-199 medium and cultured in fresh medium under an atmosphere of 5\% $\mathrm{CO}_{2}$ in air at $38.5^{\circ} \mathrm{C}$.

\section{Parthenogenetic activation of oocytes and embryo culture}

After 42-44 h of culture, the cumulus cells were removed physically from the oocytes using a narrow pipette combined with $0.1 \%$ hyaluronidase. Oocytes with a first polar body were selected and placed between $0.2 \mathrm{~mm}$ diameter platinum electrodes $1 \mathrm{~mm}$ apart in fusion activation medium and then subjected to a single DC pulse for $30 \mu \mathrm{s}$ (1,500 V/cm; ECM 2001, BTX Inc., San Diego, CA, USA) [25]. Activated oocytes were then immediately transferred into embryo culture medium PZM3 supplemented with $7.5 \mu \mathrm{g} / \mathrm{mL}$ cytochalasin B and $10 \mu \mathrm{g} / \mathrm{mL}$ CHX and cultured for $4 \mathrm{~h}$. Embryos were then cultured in groups of 15-20 per $100 \mu \mathrm{L}$ of PZM3 under sterile mineral oil for 3 days (cleavage stage) or 7 days (blastocyst stage) at $38.5^{\circ} \mathrm{C}$ under $5 \% \mathrm{CO}_{2}$ in air.

\section{Statistical analysis}

All data are presented as the mean \pm SEM, determined from a minimum of three independent experimental replicates. Data were analyzed by one-way analysis of variance (ANOVA) using SAS 9.2 software (SAS Institute, Cary, NC, USA) and $P<0.05$ was considered statistically significant.

\section{Results}

Expression and subcellular localization of $\mathrm{PAK} 1^{\text {Thr423 }}$ during porcine oocyte meiotic maturation

To investigate the role of PAK 1 and PAK $1^{\text {Thr423 }}$ during porcine oocyte meiotic maturation, we examined their expression by western blotting. We analyzed porcine oocytes at 0 , 18,30 and $44 \mathrm{~h}$, corresponding to the GV, GVBD, MI and MII stages, respectively. As shown in Figure 1A, high and stable levels of PAK 1 and PAK $1^{\text {Thr } 423}$ expression were detected from the GV to the MII stages.

To examine the subcellular localization of PAK $1^{\text {Thr423, }}$ we performed immunofluorescent staining of porcine oocytes at different stages of maturation. As shown in Figure $1 \mathrm{~B}, \mathrm{PAK} 1^{\mathrm{Thr} 423}$-immunopositive staining was initially detected around the nucleolus at the GV stage and then was closely colocalized with the chromosomes from the pro-MI to MII stage. Taken together, our immunofluorescence analysis and western blot results were consistent and revealed that the pattern of PAK $1^{\text {Thr423 }}$ distribution was closely related to meiotic progression, especially nuclear dynamics, in porcine oocytes.

\section{Expression of $\mathrm{H}^{\mathrm{Ser} 10}$ and its colocalization with} PAK1 ${ }^{\text {Thr423 }}$ in porcine oocytes during meiotic maturation It has been demonstrated that PAK ${ }^{\text {Thr423 }}$ phosphorylates the downstream factor $\mathrm{H} 3{ }^{\mathrm{Ser} 10}$ in human breast cancer cells [21]. Here, we examined the temporal and spatial distribution of $\mathrm{H}_{3}{ }^{\mathrm{Ser} 10}$, as well as its association with PAK $1^{\mathrm{Thr} 423}$ at different stages of porcine oocyte meiosis. As shown in Figure $2 \mathrm{~A}$, immunofluorescent staining confirmed that the 


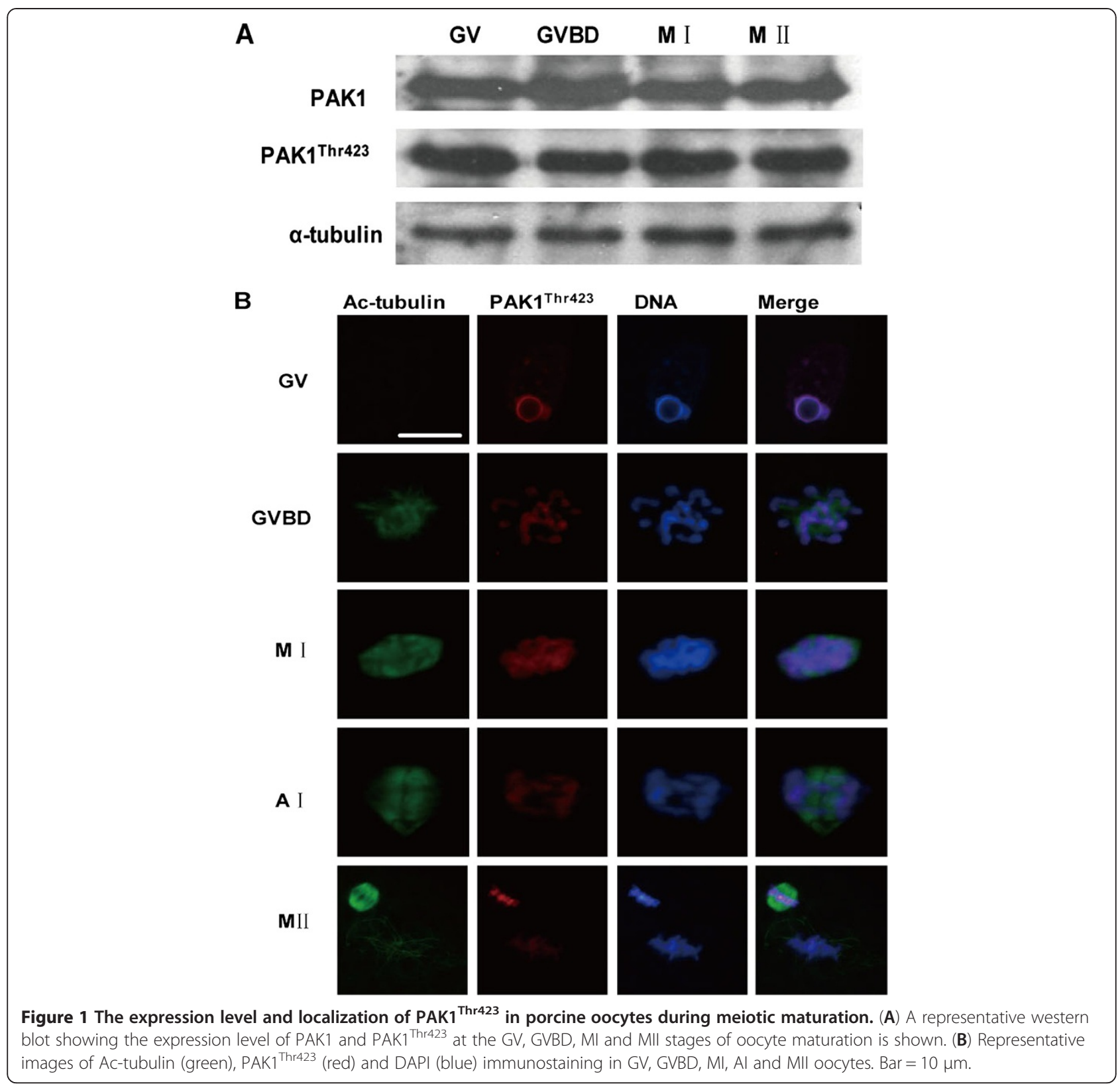

expression of PAK $1^{\text {Thr423 }}$ preceded that of $\mathrm{H} 3^{\text {Ser10 }}$ in oocytes. Compared with PAK $1^{\mathrm{Thr} 423}$, only faint $\mathrm{H} 3^{\mathrm{Ser} 10}$ expression was observed at the GV stage; however, by the GVBD stage $\mathrm{H}^{\mathrm{Ser} 10}$ expression had increased dramatically and it colocalized with PAK $1^{\text {Thr423 }}$ and the chromosomes. Specifically, it appeared that $\mathrm{H} 3^{\mathrm{Ser} 10}$ was concentrated on condensing chromatin and individual chromosomes during the pro-MI to MII stages. These results were consistent with results from our western blot analysis (Figure 2B), which revealed an extremely low level of $\mathrm{H}^{\mathrm{Ser} 10}$ expression at the GV stage that then increased progressively at the MI and MII stages. As in the results of Figure 1A, we also demonstrated a high and stable expression level of PAK $1^{\text {Thr423 }}$ from the GV to MII stage. Through our analysis of chromosomal spreading, we verified that PAK1 $1^{\text {Thr423 }}$ colocalizes with $\mathrm{H}^{\mathrm{Ser} 10}$ on chromosomes in porcine oocytes (Figure $2 \mathrm{C}$ ). Taken together, these results indicate a unique temporal and spatial correlation in the expression patterns of PAK $1^{\text {Thr423 }}$ and $\mathrm{H} 3^{\text {Ser10 }}$.

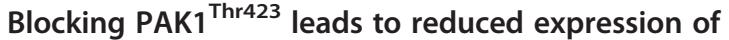
$\mathrm{H} 3^{\mathrm{Ser} 10}$, but has no impact on chromosome configuration in porcine oocytes

To block PAK1 ${ }^{\text {Thr423 }}$ activity, we microinjected an antiPAK $1^{\text {Thr423 }}$ antibody into the cytoplasm of GV stage porcine oocytes, then analyzed the effects on $\mathrm{H}^{\mathrm{Ser} 10}$ expression and oocyte maturation. Our results showed that the expression level of $\mathrm{H} 3^{\mathrm{Ser} 10}$ was dramatically reduced in 


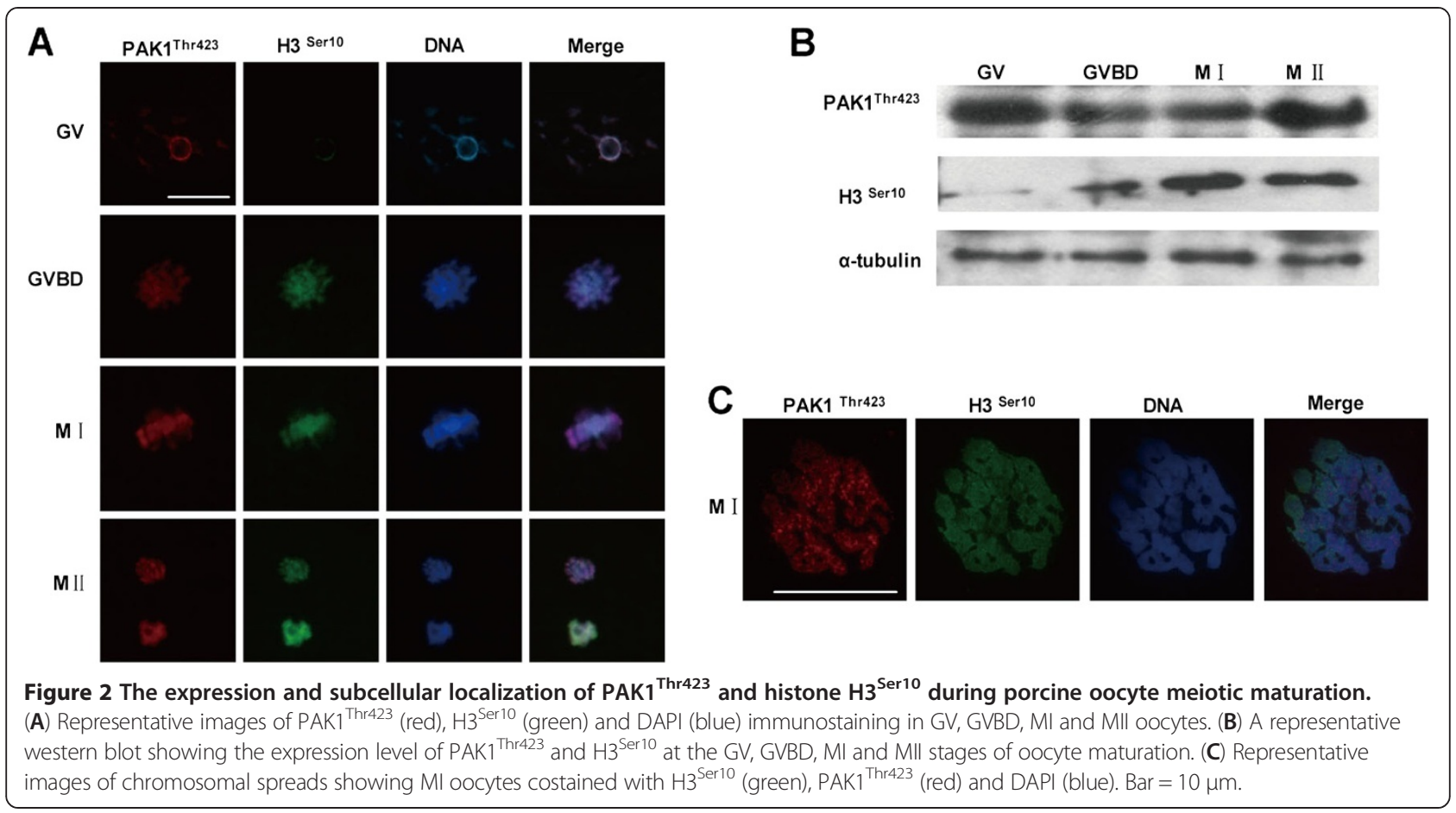

the antibody-injected oocytes compared with the control oocytes (Figure $3 \mathrm{~A}$ ), implying that PAK $1^{\text {Thr423 }}$ activity is required for the phosphorylation of $\mathrm{H}_{3}{ }^{\mathrm{Ser} 10}$.

To determine whether the reduction in $\mathrm{H} 3^{\mathrm{Ser} 10}$ expression following anti-PAK $1^{\text {Thr423 }}$ antibody injection had an effect on chromosome configuration, the chromosome structure was assayed after $44 \mathrm{~h}$ in culture (Figure 3B). As shown in Table 1 , there was no statistically significant effect of anti-PAK $1^{\text {Thr423 }}$ antibody injection on chromosome structure and formation, although there were fewer oocytes with a normal chromosome configuration in the anti-PAK $1^{\text {Thr423 }}$ antibody-injected group $0.777 \pm 0.041$, compared with the two control groups (rabbit IgGinjected and non-injected groups; $0.819 \pm 0.028$ and $0.833 \pm 0.051$, respectively)

\section{Loss of PAK1 ${ }^{\text {Thr423 }}$ activity has no influence on oocyte} meiotic progression and early embryo development We next investigated whether the reduction in $\mathrm{H}^{\mathrm{Ser} 10}$ expression following antibody injection had any effect on oocyte meiotic progression and early embryo development. As shown in Table 1, although there was a trend for a higher percentage of oocytes at the MI stage and a lower percentage of oocytes at the MII stage following antiPAK $1^{\text {Thr423 }}$ antibody injection, compared with the control groups, these differences were not statistically significant. Similarly, activated oocytes were cultured for 3 and 7 days in PZM3 medium and the rates of embryo cleavage and blastocyst formation were assessed (Table 1). Oocytes injected with the anti-PAK $1^{\text {Thr423 }}$ antibody had lower rates

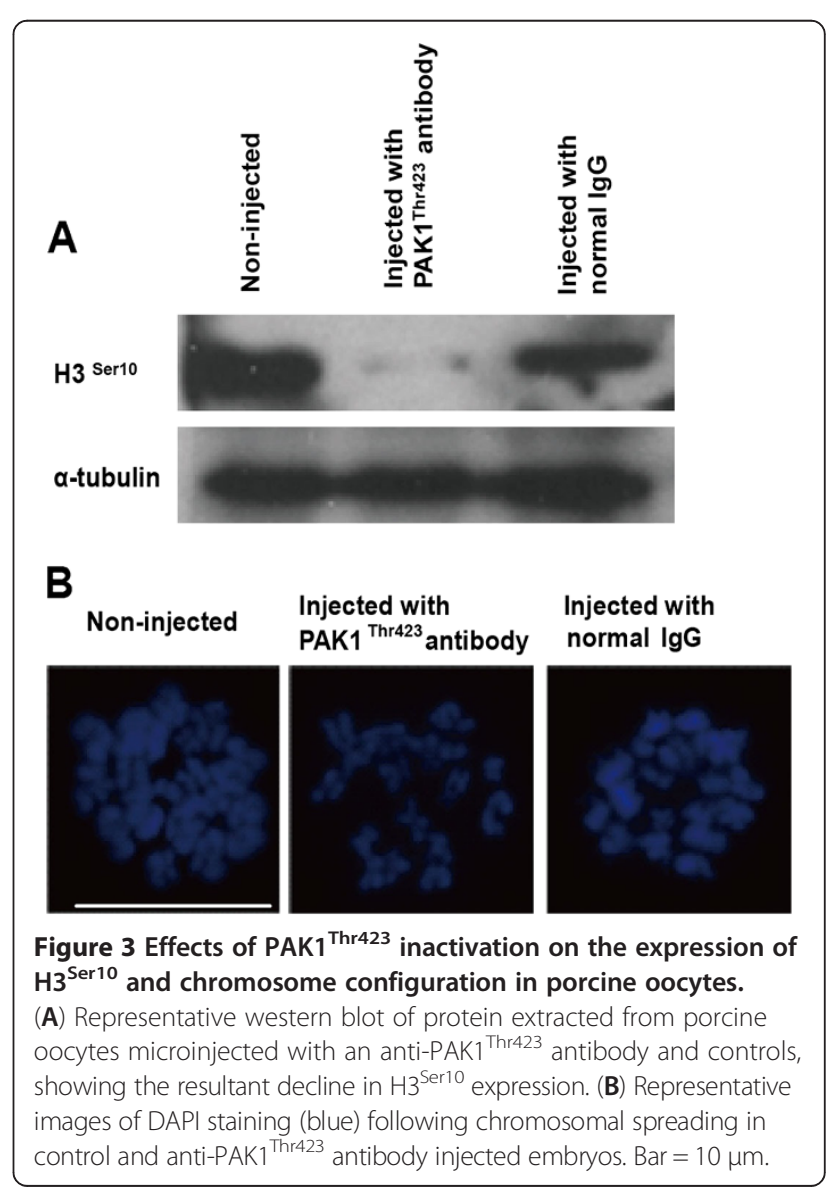




\begin{tabular}{|c|c|c|c|c|c|}
\hline \multirow[t]{2}{*}{ Treatment } & \multirow{2}{*}{$\begin{array}{l}\text { No. of } \\
\text { normal } \\
\text { oocytes (\%) }\end{array}$} & \multicolumn{2}{|c|}{ No. (\%)of oocytes at stage of } & \multirow{2}{*}{$\begin{array}{l}\text { No. of cleaved } \\
\text { embryos (\%) }\end{array}$} & \multirow{2}{*}{$\begin{array}{l}\text { No. of } \\
\text { blastocysts(\%) }\end{array}$} \\
\hline & & MI & MII & & \\
\hline Non-injected & $76(83.3 \pm 5.1)^{a}$ & $79(24.7 \pm 12.3)^{a}$ & $207(65.8 \pm 10.1)^{\mathrm{a}}$ & $229(91.3 \pm 8.0)^{a}$ & $80(28.1 \pm 6.6)^{b}$ \\
\hline Injected with normal lgG & $81(81.9 \pm 2.8)^{a}$ & $82(24.6 \pm 9.7)^{a}$ & $216(65.5 \pm 10.0)^{a}$ & $221(90.3 \pm 4.6)^{a}$ & $62(25.0 \pm 7.2)^{b}$ \\
\hline Injected with PAK1 ${ }^{\text {Thr } 423}$ antibody & $97(77.7 \pm 4.1)^{\mathrm{a}}$ & $124(30.4 \pm 7.2)^{a}$ & $251(59.1 \pm 8.0)^{a}$ & $266(88.6 \pm 4.0)^{\mathrm{a}}$ & $54(18.6 \pm 8.1)^{b}$ \\
\hline
\end{tabular}

The values are the mean \pm SEM of five independent replicates. Within the same column, values with different superscript letters are significantly different $(P<0.05)$.

of embryo cleavage and blastocyst formation compared with control oocytes; however, these differences were not statistically significant. Taken together, this data implies that PAK1 ${ }^{\text {Thr423 }}$ activity might be not essential for meiotic progression in porcine oocytes.

\section{Discussion}

In this study, we provide evidence for the first time that the activity of autophosphorylated PAK ${ }^{\text {Thr } 423}$ contributes to the phosphorylation of Histone $\mathrm{H} 3{ }^{\text {Ser10 }}$ during porcine oocyte meiotic maturation. Although $\mathrm{PAK}^{\mathrm{Thr} 423}$ and $\mathrm{H} 3^{\mathrm{Ser} 10}$ were perfectly colocalized on the chromosomes, the blockade of PAK1 $1^{\text {Thr423 }}$ and consequent reduction in $\mathrm{H} 3{ }^{\mathrm{Ser} 10}$ expression had no significant effect on chromosome configuration, meiotic progression or early embryo development.

Chromatin condensation is the first step in oocyte nuclear maturation and is required for the correct segregation of chromosomes during meiosis. The phosphorylation of histone $\mathrm{H} 3$ is thought to be involved in chromatin condensation, chromosome congregation and segregation during mitotic cell division and oocyte meiosis [26-28]. The phosphorylation of $\mathrm{H}_{3}{ }^{\mathrm{Ser} 10}$ has been suggested to play a key role in this process $[4,5]$. For example, Wang et al. observed that $\mathrm{H} 3{ }^{\mathrm{Ser} 10}$ colocalized with chromatin in the GV at prophase I of meiosis in mouse oocytes, and then became distributed along entire chromosomes with intensive aggregation in the pericentromeric heterochromatin from the pro-MI to MII stages [13]. However, Swain et al. could not detect any $\mathrm{H} 3{ }^{\mathrm{Ser} 10}$ expression in mouse oocytes at the GV stage [7]. During porcine oocyte maturation, a low level of $\mathrm{H}^{\mathrm{Ser} 10}$ has been observed at the GV stage, which significantly increased upon GVBD; furthermore, $\mathrm{H} 3^{\mathrm{Ser} 10}$ was also shown to tag intact chromosomes from the pro-MI to MII stages $[2,7,9]$. These results are in agreement with our findings, as only extremely low levels of $\mathrm{H}^{\mathrm{Ser} 10}$ expression were detected at the GV stage, but it increased dramatically at the MI and MII stages. The concurrence of elevated $\mathrm{H} 3^{\mathrm{Ser} 10}$ and chromatin remodeling upon GVBD implies that the activity of $\mathrm{H}^{\mathrm{Ser} 10}$ might be required for chromatin condensation into individual chromosomes.

Histone H3 can be phosphorylated by several kinases. Thus, Aurora B is required for histone $\mathrm{H} 3$ phosphorylation during mitosis in Drosophila [29] and Xenopus [30] and plays a central role in the assembly and maintenance of mitotic chromosome structure. As a substrate of PAK1 $1^{\text {Thr423, }}$ histone $\mathrm{H} 3$ can be phosphorylated at Ser10 in human breast cancer cells [21]. In the current study, immunofluorescence analysis and western blotting confirmed that autophosphorylation of PAK $1^{\text {Thr423 }}$ preceded phosphorylated $\mathrm{H} 3{ }^{\mathrm{Ser} 10}$ expression during porcine oocyte maturation, and that PAK $1^{\text {Thr423 }}$ was stably expressed and colocalized with $\mathrm{H} 3^{\mathrm{Ser} 10}$ on chromosomes. We also found that the expression of $\mathrm{H}^{\text {Ser10 }}$ was decreased in porcine oocytes microinjected with an anti-body against PAK1 ${ }^{\text {Thr423, }}$, indicating that the activity of PAK $1{ }^{\text {Thr423 }}$ regulates the $\mathrm{H} 3{ }^{\text {Ser10 }}$, which is consistent with findings in human cancer cells [21].

Given these prior findings, we hypothesized that PAK1 $1^{\text {Thr423 }}$ might play a role in chromatin remodeling and separation in porcine oocyte meiosis by phosphorylating $\mathrm{H}^{\mathrm{Ser} 10}$. Unfortunately, this hypothesis had to be rejected based on our results, as oocytes microinjected with anti-PAK $1^{\text {Thr423 }}$ antibodies displayed no significant changes in chromosome configuration, rates of meiotic progression or subsequent early embryonic development, despite having a reduced level of $\mathrm{H} 3{ }^{\mathrm{Ser} 10}$ expression.

Bui et al. [14] claimed that the activity of $\mathrm{H}^{\mathrm{Ser10}}$ was related to chromatin remodeling in porcine oocytes. Similarly, increased $\mathrm{H}_{3}^{\mathrm{Ser} 10}$ expression following treatment with a PP1/2a inhibitor was associated with chromatin condensation in mouse oocytes [6]. Despite these data, our results indicated that $\mathrm{H}^{\mathrm{Ser} 10}$ was not essential in these processes. In agreement with this conclusion, Jelínková et al. found that $\mathrm{H} 3{ }^{\mathrm{Ser} 10}$ was not essential for chromatin condensation to chromosomes upon the resumption of meiosis in porcine oocytes [9]. The studies of Bui et al. and Swain et al. both used chemical inhibitors to alter the intracellular level of $\mathrm{H}^{\mathrm{Ser} 10}$ in oocytes. Thus, it is hard to rule out the possibility that other kinases or pathways essential for chromatin remodeling were affected [6,14]. Accordingly, such nonspecific effects could have affected chromatin structure independently of the effect on $\mathrm{H} 3{ }^{\mathrm{Ser} 10}$. In our study, the depletion of $\mathrm{H}^{\mathrm{Ser} 10}$ by microinjection with a specific antibody against PAK $1^{\text {Thr423 }}$ provided a more targeted approach. Thus, in agreement with Jelínková et al., we believe 
the activity of $\mathrm{H}^{\mathrm{Ser} 10}$ does not play an essential role in chromatin remodeling during meiosis in pig oocytes [9].

\section{Conclusions}

Our results clearly demonstrate that PAK $1^{\text {Thr } 423}$ regulates the phosphorylation of $\mathrm{H}^{\mathrm{Ser} 10}$ in porcine oocytes. Despite this interaction, our results suggest that the PAK $1^{\text {Thr423 }}$ $\mathrm{H} 3{ }^{\mathrm{Ser} 10}$ pathway is not essential for the maintenance of chromosome configuration and meiotic progression in pig oocytes, or for early embryo development.

\section{Competing interests}

The authors declare that they have no competing interests.

\section{Authors' contributions}

BYW as the lead author designed the research protocol, carried out the experiments, collected and analyzed data and drafted the manuscript. WM was instrumental in guiding the experiment skills. XLX, CW, YBZ and NA participated in carrying out all the lab work, data collection and analysis. WM, LA, ZHW and JHT gave significant contributions to designing the study. All authors have read and approved the final manuscript.

\section{Acknowledgments}

This study was supported by grants from the National High-Tech R\&D Program (No. 2011AA100303), the National Key Technology R\&D Program (No. 2011BAD19B01) and the National Natural Science Foundation of China (No. 31271253).

\section{Author details}

'Ministry of Agriculture Key Laboratory of Animal Genetics, Breeding and Reproduction; National Engineering Laboratory for Animal Breeding, College of Animal Science and Technology, China Agricultural University, Beijing 100193, P. R. China. ${ }^{2}$ Institute of Animal Husbandry and Veterinary Medicine, Beijing Municipal Academy of Agriculture and Forestry Sciences, Beijing 100097, P. R. China. ${ }^{3}$ Department of Histology and Embryology; School of Basic Medical Sciences, Capital Medical University, Beijing 100069, P. R. China.

Received: 25 January 2013 Accepted: 1 March 2013

Published: 22 March 2013

\section{References}

1. Tan JH, Wang HL, Sun XS, Liu Y, Sui HS, Zhang J: Chromatin configurations in the germinal vesicle of mammalian oocytes. Mol Hum Reprod 2009, 15:1-9.

2. Gu L, Wang Q, Sun QY: Histone modifications during mammalian oocyte maturation: dynamics, regulation and functions. Cell Cycle 2010, 9:1942-1950.

3. Hendzel MJ, Wei Y, Mancini MA, Van Hooser A, Ranalli T, Brinkley BR, BazettJones DP, Allis CD: Mitosis-specific phosphorylation of histone H3 initiates primarily within pericentromeric heterochromatin during $\mathrm{G} 2$ and spreads in an ordered fashion coincident with mitotic chromosome condensation. Chromosoma 1997, 106:348-360

4. Wei Y, Mizzen CA, Cook RG, Gorovsky MA, Allis CD: Phosphorylation of histone $\mathrm{H} 3$ at serine 10 is correlated with chromosome condensation during mitosis and meiosis in Tetrahymena. Proc Natl Acad Sci USA 1998 95:7480-7484.

5. Wei Y, Yu L, Bowen J, Gorovsky MA, Allis CD: Phosphorylation of histone $\mathrm{H} 3$ is required for proper chromosome condensation and segregation. Cell 1999, 97:99

6. Swain JE, Ding J, Brautigan DL, Villa-Moruzzi E, Smith GD: Proper chromatin condensation and maintenance of histone $\mathrm{H} 3$ phosphorylation during mouse oocyte meiosis requires protein phosphatase activity. Biol Reprod 2007, 76:628-638.

7. Bui HT, Van Thuan N, Kishigami S, Wakayama S, Hikichi T, Ohta H, Mizutani E, Yamaoka E, Wakayama T, Miyano T: Regulation of chromatin and chromosome morphology by histone H3 modifications in pig oocytes. Reproduction 2007, 133:371-382.

8. Wang Q, Ai JS, Ola SI, Gu L, Zhang YZ, Chen DY, Sun QY: The spatial relationship between heterochromatin protein 1 alpha and histone modifications during mouse oocyte meiosis. Cell Cycle 2008, 7:513-520.
9. Jelínková L, Kubelka M: Neither Aurora B activity nor histone H3 phosphorylation is essential for chromosome condensation during meiotic maturation of porcine oocytes. Biol Reprod 2006, 74:905-912.

10. He Z, Cho YY, Ma WY, Choi HS, Bode AM, Dong Z: Regulation of ultraviolet B-induced phosphorylation of histone $\mathrm{H} 3$ at serine 10 by Fyn kinase. J Biol Chem 2005, 280:2446-2454.

11. Schmitt A, Gutierrez GJ, Lénárt P, Ellenberg J, Nebreda AR: Histone H3 phosphorylation during $<\mathrm{i}>$ Xenopus $</ \mathrm{i}>$ oocyte maturation: regulation by the MAP kinase/p90Rsk pathway and uncoupling from DNA condensation. FEBS Lett 2002, 518:23-28.

12. George O, Johnston MA, Shuster CB: Aurora B kinase maintains chromatin organization during the MI to MII transition in surf clam oocytes. Cell Cycle 2006, 5:2648-2656.

13. Wang Q, Wang CM, Ai JS, Xiong B, Yin S, Hou Y, Chen DY, Schatten H, Sun QY: Histone phosphorylation and pericentromeric histone modifications in oocyte meiosis. Cell Cycle 2006, 5:1974-1982.

14. Bui HT, Yamaoka E, Miyano T: Involvement of histone H3 (Ser10) phosphorylation in chromosome condensation without Cdc2 kinase and mitogen-activated protein kinase activation in pig oocytes. Biol Reprod 2004, 70:1843-1851.

15. Manser E, Leung T, Salihuddin H, Zhao Z, Lim L: A brain serine/threonine protein kinase activated by Cdc42 and Rac1. Nature 1994, 367:40-46.

16. Knaus UG, Bokoch GM: The p21Rac/Cdc42-activated kinases (PAKs). Int J Biochem Cell B 1998, 30:857.

17. Hofmann C, Shepelev M, Chernoff J: The genetics of Pak. J Cell Sci 2004, 117:4343-4354.

18. Lei M, Lu W, Meng W, Parrini MC, Eck MJ, Mayer BJ, Harrison SC: Structure of PAK1 in an autoinhibited conformation reveals a multistage activation switch. Cell 2000, 102:387-397.

19. Bokoch GM: Biology of the p21-activated kinases. Annu Rev Biochem 2003, 72:743-781.

20. Hubsman MW, Volinsky N, Manser E, Yablonski D, Aronheim A: Autophosphorylation-dependent degradation of Pak1, triggered by the Rho-family GTPase. Chp. Biochem J 2007, 404:487.

21. Li F, Adam L, Vadlamudi RK, Zhou H, Sen S, Chernoff J, Mandal M, Kumar R: p21-activated kinase 1 interacts with and phosphorylates histone $\mathrm{H} 3$ in breast cancer cells. EMBO Rep 2002, 3:767-773.

22. Lin SL, Qi ST, Sun SC, Wang YP, Schatten H, Sun QY: PAK1 regulates spindle microtubule organization during oocyte meiotic maturation. Front Biosci 2010, 2:1254

23. Naito $\mathrm{K}$, Toyoda Y: Fluctuation of histone $\mathrm{H} 1$ kinase activity during meiotic maturation in porcine oocytes. J Reprod Fertil 1991, 93:467-473.

24. Liu JJ, Ma X, Cai LB, Cui YG, Liu JY: Downregulation of both gene expression and activity of Hsp27 improved maturation of mouse oocyte in vitro. Reprod Biol Endocrin 2010, 8:47.

25. Park KW, Lai L, Cheong HT, Im GS, Sun QY, Wu G, Day BN, Prather RS: Developmental potential of porcine nuclear transfer embryos derived from transgenic fetal fibroblasts infected with the gene for the green fluorescent protein: comparison of different fusion/activation conditions. Biol Reprod 2001, 65:1681-1685.

26. Earnshaw WC, Bernat RL: Chromosomal passengers: toward an integrated view of mitosis. Chromosoma 1991, 100:139-146.

27. De La Barre AE, Gerson V, Gout S, Creaven M, Allis CD, Dimitrov S: Core histone $\mathrm{N}$-termini play an essential role in mitotic chromosome condensation. EMBO J 2000, 19:379-391.

28. Adams RR, Carmena M, Earnshaw WC: Chromosomal passengers and the (aurora) ABCs of mitosis. Trends Cell Biol 2001, 11:49.

29. Giet $R$, Glover DM: Drosophila aurora B kinase is required for histone H3 phosphorylation and condensin recruitment during chromosome condensation and to organize the central spindle during cytokinesis. J Cell Biol 2001, 152:669-682.

30. Murnion ME, Adams RR, Callister DM, Allis CD, Earnshaw WC, Swedlow JR: Chromatin-associated protein phosphatase 1 regulates aurora- $B$ and histone H3 phosphorylation. J Biol Chem 2001, 276:26656-26665.

\section{doi:10.1186/2049-1891-4-13}

Cite this article as: Wang et al:: Phosphorylation of histone H3 on Ser10 by auto-phosphorylated PAK1 is not essential for chromatin condensation and meiotic progression in porcine oocytes. Journal of Animal Science and Biotechnology 2013 4:13. 